\title{
How Attributional Ambiguity Shapes Physiological and Emotional Responses to Social Rejection and Acceptance
}

\section{Citation}

Mendes, Wendy B., Brenda Major, Shannon McCoy, and Jim Blascovich. 2008. How attributional ambiguity shapes physiological and emotional responses to social rejection and acceptance. Journal of Personality and Social Psychology 94(2): 278-291.

\section{Published Version}

http://dx.doi.org/10.1037/0022-3514.94.2.278

\section{Permanent link}

http://nrs.harvard.edu/urn-3:HUL.InstRepos:3119434

\section{Terms of Use}

This article was downloaded from Harvard University's DASH repository, and is made available under the terms and conditions applicable to Other Posted Material, as set forth at http:// nrs.harvard.edu/urn-3:HUL.InstRepos:dash.current.terms-of-use\#LAA

\section{Share Your Story}

The Harvard community has made this article openly available.

Please share how this access benefits you. Submit a story.

\section{Accessibility}




\title{
How Attributional Ambiguity Shapes Physiological and Emotional Responses to Social Rejection and Acceptance
}

\author{
Wendy Berry Mendes \\ Harvard University
}

\author{
Shannon McCoy \\ University of Maine
}

\author{
Brenda Major \\ University of California, Santa Barbara \\ Jim Blascovich \\ University of California, Santa Barbara
}

\begin{abstract}
The authors examined White and Black participants' emotional, physiological, and behavioral responses to same-race or different-race evaluators, following rejecting social feedback or accepting social feedback. As expected, in ingroup interactions, the authors observed deleterious responses to social rejection and benign responses to social acceptance. Deleterious responses included cardiovascular (CV) reactivity consistent with threat states and poorer performance, whereas benign responses included $\mathrm{CV}$ reactivity consistent with challenge states and better performance. In intergroup interactions, however, a more complex pattern of responses emerged. Social rejection from different-race evaluators engendered more anger and activational responses, regardless of participants' race. In contrast, social acceptance produced an asymmetrical race pattern-White participants responded more positively than did Black participants. The latter appeared vigilant and exhibited threat responses. Discussion centers on implications for attributional ambiguity theory and potential pathways from discrimination to health outcomes.
\end{abstract}

Keywords: intergroup interactions, discrimination, attributional ambiguity, emotion and stress responses, cardiovascular reactivity

Responses to social rejection and social acceptance may seem obvious - the former is bad and the latter is good. However, this simple heuristic may not be relevant for all social interactions, especially interracial ones. Social rejection by an outgroup member (i.e., different-race partner) may be construed a variety of ways, including a sense that one's self was rejected, that one's group was rejected, or that one's partner was biased (e.g., racist). Ingroup rejection, in contrast, is unlikely to be interpreted at a group level and is more likely to engender a person-level attribution (e.g., self-blame). Social acceptance may also not be straightforward. To be sure, social acceptance by an ingroup member is likely to be perceived positively and to instill good feelings. However, social acceptance by an outgroup member may be viewed cautiously, with individuals questioning the genuineness of the evaluation, possibly undermining the positive feelings typically

Wendy Berry Mendes, Department of Psychology, Harvard University; Brenda Major and Jim Blascovich, Department of Psychology, University of California, Santa Barbara; Shannon McCoy, Department of Psychology, University of Maine.

The research was supported by National Heart, Lung, and Blood Institute Grant RO1 HL079383 awarded to Wendy Berry Mendes and Brenda Major. We are grateful to our dedicated confederates and research assistants at University of California, Santa Barbara and at Harvard University for their assistance in conducting the experiments, scoring the physiological data, and coding behavior.

Correspondence concerning this article should be addressed to Wendy Berry Mendes, Department of Psychology, Harvard University, 33 Kirkland Street, 1420 William James Hall, Cambridge, MA 02138. E-mail: wbm@wjh.harvard.edu associated with social acceptance. In this research, we explored how social rejection and acceptance are perceived, are responded to, and affect an ongoing social interaction between same-race or different-race interaction partners.

\section{Intraracial Interactions Versus Interracial Interactions}

Social interactions with partners of different races have been known to produce stress, threat, and anxiety (e.g., Ickes, 1984; Mendes, Blascovich, Lickel, \& Hunter, 2002; Stephan \& Stephan, 2000). A growing body of research has demonstrated that individuals interacting with or exposed to outgroup members exhibit more negatively toned responses. For example, White participants engaged in cooperative social interactions with Black partners exhibited cardiovascular $(\mathrm{CV})$ reactivity consistent with the psychological state of threat and performed less well on a cognitive task than did White participants interacting with White partners, who exhibited a benign CV pattern related to challenge states (Blascovich, Mendes, Hunter, Lickel, \& Kowai-Bell, 2001; Mendes et al., 2002).

These effects do not seem to be limited to majority members interacting with minority members. Richeson, Shelton, and their colleagues (Richeson \& Shelton, 2003; Richeson, Trawalter, \& Shelton, 2005) found that both White and Black participants showed a reduction in their ability to inhibit Stroop responses following interactions with outgroup partners relative to interactions with ingroup partners. These authors interpreted this failure of inhibition as demonstrating that intergroup interactions require more effortful regulation than do ingroup interactions. 
It is important to note that these examples featured an evaluatively neutral paradigm. For example, in the CV studies, the confederates were instructed to behave neutrally during the interaction. Such neutral interactions allow for more ambiguity regarding how one is evaluated or regarded. In contrast, in the current study, we examined interracial encounters in which participants experienced explicit social rejection or social acceptance. We reasoned that the complexity of the attributions for and responses to this feedback would differ dramatically, depending on whether it occurred within a same-race or a different-race context (see Crocker \& Major, 1989).

\section{Social Evaluation in Ingroup Interactions}

Therapists, teachers, and grandmothers all know that when people receive positive social feedback they are likely to feel better about themselves than when they receive negative social feedback (e.g., rejection or ostracism). Likewise, psychological research has shown that social acceptance versus social rejection differentially affect mood, self-esteem, behavior, and physiology (Crocker, Cornwell, \& Major, 1993; Dickerson, Gruenewald, \& Kemeny, 2004; Leary et al., 2003). Indeed, social acceptance is so central to well-being that the need to belong to social groups, an implicit form of social acceptance, is recognized as an important social motive in humans and primates (e.g., Baumeister \& Leary, 1995; Cheney, Seyfarth, \& Smuts, 1986)

In contrast, social rejection is painful and typically engenders internal negative emotions like shame, sadness, and even depression (Ayduk, Mischel, \& Downey, 2002; Williams, 2001). Social rejection, including ostracism, exclusion, and loneliness, has farreaching negative effects on physical health (Cacioppo, Hawkley, \& Bernston, 2003; Stroud, Tanofsky-Kraff, Wilfley, \& Salovey, 2000) and mental health (Williams, 2001). Social rejection has been shown to influence neural activation, as well. In one study, participants who were ostracized exhibited increased regional activity in the anterior cingulate cortex, an area of the brain that is also active during physical pain (Eisenberger, Lieberman, \& Williams, 2003). These findings suggest that social acceptance can lead to positive feelings and benign responses, whereas social rejection is likely to lead to internal negative emotions and more malignant responses.

\section{Social Evaluation in Intergroup Interactions}

But how are social acceptance and rejection construed in intergroup interactions? Although the use of social acceptance and rejection paradigms to create positive and negative affective states has been ubiquitous in psychological research, social evaluation has typically been examined within same-race interactions or without regard to the intergroup context. A notable early exception is research by Crocker, Voelkl, Testa, and Major (1991). In their study, Black participants and White participants were socially accepted or socially rejected by a White partner (confederate) who the participant believed was either aware or unaware of the participant's race. Black participants who were rejected by a White partner who they believed knew their race attributed the feedback to discrimination more frequently than did participants in any other condition, and their self-esteem did not decrease from preexperiment levels. These authors reasoned that the ability of Black participants to attribute negative feedback to discrimination could protect their self-esteem from rejection. The importance of this article notwithstanding, this research was imbalanced in that majority group members' reactions to positive or negative feedback were examined within an intraracial encounter, whereas minority group members' reactions were examined within an interracial encounter. This leaves unanswered whether this effect is an intergroup phenomenon or a phenomenon related to minority group status.

\section{Social Rejection From an Outgroup Member}

Though rejection from an ingroup member is likely to engender internal negative emotions (i.e., internalization) and self-blame, rejection within the context of an intergroup interaction may evoke external negative emotions (i.e., externalization) such as anger. This may occur because interracial interactions are more attributionally ambiguous and thus bring about more possible reasons for rejection, including the attribution that one may have experienced discrimination (Crocker \& Major, 1989). Attributions to discrimination may shift explanations for the cause of rejection from internal reasons to external ones, thereby protecting self-esteem (Major, Quinton, \& Schmader, 2003). Although attributing rejection to discrimination can protect self-esteem, it can also lead to increased anger (Major, Quinton, \& McCoy, 2002). Indeed, anger has been identified as the most common emotional state to follow perceptions of racism (Bullock \& Houston, 1987; see also Clark Anderson, Clark, \& Williams, 1999).

\section{Social Acceptance From an Outgroup Member}

Though counterintuitive, evidence is mounting that social acceptance from outgroup members may not always translate into benign or positive affective consequences. Indeed, Crocker et al. (1991) found significant drops in self-esteem among Black participants who received positive evaluations from White partners who could see them and hence knew their race. Similarly, Cohen and colleagues (G. L. Cohen, Steele, \& Ross, 1999) found that Black participants receiving critical feedback plus praise for a written essay perceived the evaluator to be higher in bias, and they were more likely to disidentify from the evaluated domain than were White participants receiving similar feedback. These studies suggested that positive feedback might be discounted within an interracial interaction.

Another potential pitfall of positive feedback in the interracial context is that such feedback may be perceived as overcorrecting (Vorauer \& Turpie, 2004). White participants may be motivated to appear nonprejudiced and, in trying to be nonprejudiced, may act overly friendly (Plant \& Devine, 1998). They may also be motivated to distort their responses because of political correctness concerns and, as a result, may behave in ways that do not reflect their true feelings. The disingenuousness of these actions may be detected by Blacks, increasing feelings of uncertainty regarding the cause of social acceptance.

Examining how people respond to interracial acceptance and rejection is complicated by several factors. As noted above, interracial interactions are prone to deliberate distortions in responses, such that participants may be unwilling to report their true thoughts and feelings for fear of appearing prejudiced. People may 
also be motivated to claim that they were not a target of discrimination because in so doing they may suffer social costs, such as being perceived as a whiner or troublemaker (Kaiser \& Miller, 2001). Furthermore, repression-claiming to not feel anxious or stressed coupled with high defensiveness-may be a common coping response to prejudice, leading to self-reports of positive emotion and well-being while nonetheless taking a physical toll on the body (Barger, Marsland, Bachen, \& Manuck, 2000; Weinberger, Schwartz, \& Davidson, 1979). Thus, evaluation apprehension, repression, and denial of discrimination may all increase the difficulty of obtaining unexpurgated responses to acceptance and rejection during interracial encounters.

Because of these issues, we relied on multiple measures to examine responses to acceptance versus rejection in same-race interactions or different-race interactions. We included measures that are viewed as assessing more automatic responses as a way to circumvent intentional distortions between what individuals feel and think and what they self-report. We measured CV responses, cognitive performance, nonverbal behavior and emotional displays (as coded by observers), in addition to self-reports.

\section{Biopsychosocial Model of Challenge and Threat}

To ground our predictions and interpretation of multiple measures, we used a framework to organize responses associated with activational states versus inhibitional states. Challenge and threat theory (Blascovich \& Mendes, 2000; Blascovich \& Tomaka, 1996) posits that during active tasks, individuals' appraisals of situational demands relative to resources result in a cascade of $\mathrm{CV}$, hormonal, behavioral, affective, and cognitive consequences that can index motivational states associated with activational responses versus inhibitional responses.

Challenge states are activational responses and occur when personal resources exceed situational demands. Consequently, CV responses exhibited in challenge states tend to be associated with greater sympathetic adrenal medullary activation, thus increasing ventricular contractility (VC), cardiac efficiency, and vasodilation in the arterioles, which provide greater blood flow to the periphery. The CV pattern of reactivity associated with challenge is similar (if not identical) to the Pattern 1 (activational) response (see Brownley, Hurwitz, \& Schneiderman, 2000).

In contrast, threat states are inhibitional responses and result when situational demands exceed personal resources. CV reactivity exhibited in threat states consists of less efficient cardiac output (CO) and vasoconstriction. Similar to the Pattern 2 (inhibitional) response, $\mathrm{CV}$ reactivity during threat states is believed to be associated with avoidant and defeat-related motivation (Brownley et al., 2000).

Challenge and threat have typically been linked to high arousal, positive emotions and high arousal, negative emotions, respectively; more precisely, these states index motivational tendencies rather than affective states (Herrald \& Tomaka, 2002; see also Feldman Barrett, 2006) and, thus, are orthogonal to valence. Therefore, challenge responses are more likely indexing approach motivation and not necessarily positive emotion. One implication of this is that approach-negative emotions, like anger, should be more closely related to challenge than to threat (see Harmon-Jones \& Allen, 1998, for a conceptually similar argument related to prefrontal cortical asymmetry).
If both high arousal positive emotions (e.g., pride, happiness) and anger are associated with activational patterns, can they be differentiated physiologically? A search of literature on emotion specificity of autonomic nervous system revealed sparse evidence for autonomic nervous system differences in emotion (Cacioppo, Bernston, Larsen, Poehlmann, \& Ito, 2000; cf., Levenson, Ekman, \& Friesen, 1990). However, a meta-analysis by Cacioppo and colleagues (Cacioppo et al., 2000) suggested one measure that may differentiate between positive emotions and anger: heart rate (HR). Specifically, their meta-analysis showed that anger is associated with higher HR than is happiness. Another promising measure that may differentiate anger from positive emotion is VC. Sinha, Lovallo, and Parsons (1992) found greater increases in VC during anger imagery than during joy imagery. Similarly, using core relational themes, Herrald and Tomaka (2002) reported greater VC during anger than during pride. Therefore, on the basis of this literature, we predicted that within a challenge state, magnitude differences in $\mathrm{VC}$ and $\mathrm{HR}$ reactivity might differentiate anger from positive emotions. A summary of our predictions differentiating challenge and threat and differentiating, within challenge responses, positive emotions and anger are presented in Figure 1.

Integrating attributional ambiguity theory with a motivational perspective allows us to investigate effects of attributional ambiguity that were previously unclear or unspecified, as well as to extend the theory. Specifically, it is unclear why self-esteem does not decrease following attributions to discrimination. Are participants simply disengaging from the social interaction with a prejudiced person? Are the self-esteem effects observed due simply to individuals masking the pain of being a target of discrimination and self-reporting that they are not affected by the discrimination when, in reality, they are feeling anxiety and threat? Is buffered self-esteem a defensive reaction? In a motivational framework, these questions can be explored. In addition, this work examines negative affective responses that are differentiated along the lines of internal emotional responses and external emotional responses. This allows us to make more nuanced predictions regarding the effects of perceived discrimination compared with social rejection that is not perceived as discriminatory.

\begin{tabular}{|c|c|c|}
\hline \multicolumn{3}{|c|}{$\begin{array}{l}\text { Predicted Motivational, Affective, and Cardiovascular } \\
\text { Responses to Stressors }\end{array}$} \\
\hline \multicolumn{2}{|c|}{$\begin{array}{l}\text { Activation } \\
\text { Challenge } \\
\end{array}$} & \begin{tabular}{|c|} 
Inhibition \\
Threat \\
\end{tabular} \\
\hline Positive Emotions & $\begin{array}{l}\begin{array}{l}\text { Anger } \\
\text { (Externalizing) }\end{array} \\
\end{array}$ & $\begin{array}{l}\text { Threat } \\
\text { (Internalizing) } \\
\end{array}$ \\
\hline $\begin{array}{l}\text { Emotions/Motivation: } \\
\text { Confidence } \\
\text { Pride }\end{array}$ & $\begin{array}{l}\text { Emotions/Motivation: } \\
\text { External Negative } \\
\text { Emotions: Anger }\end{array}$ & $\begin{array}{l}\text { Emotions/Motivation: } \\
\text { Internal Negative Emotions: }\end{array}$ \\
\hline Approach & Approach & Avoidance, Defeat, Vigilance \\
\hline $\begin{array}{l}\text { Performance: } \\
\text { Facilitated }\end{array}$ & $\begin{array}{l}\text { Performance: } \\
\text { Facilitated }\end{array}$ & $\begin{array}{l}\text { Performance: } \\
\text { Impaired }\end{array}$ \\
\hline $\begin{array}{l}\text { CV Reactivity: } \\
\uparrow \mathrm{CO} \\
\uparrow \mathrm{VC} \\
\downarrow \mathrm{TPR} \\
\uparrow \mathrm{HR} \\
\end{array}$ & $\begin{array}{c}\text { CV Reactivity: } \\
\uparrow \mathrm{CO} \\
\uparrow \mathrm{VC} \\
\downarrow \mathrm{TPR} \\
\uparrow \mathrm{HR} \\
\end{array}$ & $\begin{array}{l}\text { CV Reactivity: } \\
\quad \leftrightarrow \mathrm{CO} \\
\uparrow \mathrm{VC} \\
\uparrow \mathrm{TPR} \\
\uparrow \mathrm{HR} \\
\end{array}$ \\
\hline
\end{tabular}

Figure 1. The up arrows refer to increases, the down arrows refer to decreases, and the side-to-side arrow refers to no change. The less than symbols indicate that the adjacent measures are relatively different from each other. $\mathrm{CV}=$ cardiovascular; $\mathrm{CO}=$ cardiac output; $\mathrm{VC}=$ ventricular contractility; TPR $=$ total peripheral resistance; HR $=$ heart rate. 


\section{Overview of Experiment and Predictions}

In the following study, White participants and Black participants arrived at the laboratory and met a White, same-sex confederate or a Black, same-sex confederate. Sensors to measure CV responses were applied and, after a baseline period, the participant delivered a speech that the confederate evaluated. After the speech, the participant received an evaluation form ostensibly completed by the confederate, which consisted of either negative (rejecting) or positive (accepting) social feedback. Participants then completed attributions for feedback. After completion of attributions, an audiovisual connection allowed the confederate and the participant to see and hear each other, and the dyad completed a cooperative task.

We predicted that same-race dyads, compared with differentrace dyads, would respond differently to accepting and rejecting feedback. Specifically, we predicted that rejection by a same-race partner would result in participants exhibiting CV responses consistent with threat, internal negative emotions (especially anxiety and shame), and poorer cognitive performance. In contrast, rejection by a different-race partner was expected to be perceived as more discriminatory and to result in more anger, better performance, and activational $\mathrm{CV}$ responses.

With respect to social acceptance, we predicted that participants would respond to social acceptance from same-race partners with generally benign reactions, including positive emotions, challenge states, and better performance. In contrast, we expected that positive social feedback from a different-race partner would be attributionally ambiguous, particularly for Black participants, who might doubt the genuineness of the feedback. Thus, we expected these participants to show inhibitional responses, such as $\mathrm{CV}$ threat responses, anxiety increases, and behavioral manifestations of vigilance.

Although our predictions for Black participants paired with White partners were clear, we were agnostic regarding whether White participants paired with Black partners would reveal the same patterns. Thus, a key question of this research was whether intergroup interaction effects were symmetrical-occurring similarly for Black participants and White participants-or asymmetrical-occurring only for Black participants in interracial interactions.

\section{Method}

\section{Setting and Participants}

A social psychophysiology laboratory served as the experimental setting. We recruited Black and White male and female undergraduate participants $(N=122 ; 49 \%$ Black and $51 \%$ White; $31 \%$ men and 69\% women) who received either course credit or $\$ 10$ and who all received a $\$ 5$ bonus (see below).

\section{Confederates}

We trained seventeen ${ }^{1}$ Black and White male and female research assistants to be confederates for this study. Some confederates were hired from a neighboring college to limit the possibility that participants would know the confederate. Every racegender combination had at least three different confederates. We instructed the confederates, who were blind to the feedback manipulation, to act interested but neutral throughout the experiment.

\section{Procedure}

Arrival. Participants arrived individually and waited with the confederate. Two experimenters emerged from the control room, confirmed the names, and introduced the participant and the confederate to each other, making sure that they did not previously know each other. At this point, one of the experimenters instructed the dyad to select from a bowl one of two cards that read either A or B. The participant and confederate showed each other what they selected, and they were then escorted to different experimental rooms, where the participant completed the consent form. The experimenter then applied the various sensors needed to record CV responses, and the participant was instructed to sit for a quiet, 5-min baseline period. At this time, the experimenter applied nonoperating sensors to the confederate because the participant and confederate would be seeing each other during the cooperative task.

Speech task. After the baseline period, the participant was instructed via intercom that the rooms would be connected so that the two could hear each other. We then played one of two prerecorded instructions for the speech task, depending on whether the participant chose the A card or the B card. The instructions revealed that the person who chose A (or B) had been assigned to the performer condition and that the person who chose $\mathrm{B}$ (or $\mathrm{A}$ ) had been assigned to the evaluator condition. The participant was always the performer. They were further instructed that the performer would have to deliver a speech on the topic of "Why I Make a Good Friend" for 2 min, after a 1-min preparation period, while the evaluator listened to the speech. The participant prepared silently for a minute, and he or she was then instructed by the experimenter to begin and to end the speech. Once the speech ended, the experimenter disconnected the audio connection.

Feedback manipulation. After the speech, the experimenter waited $3 \mathrm{~min}$ and then entered the participant's room with an envelope that he or she handed to the participant. The experimenter explained that inside the envelope was the partner's evaluation form. The participant was instructed to take out the evaluation form, to review it, and to place it back in the envelope when done. The experimenters were kept blind to the valence of the feedback form inside the envelope, and the experimenters returned to the participant's room only after the participant finished reviewing the form. The only person who knew the type of feedback was the director of the study, who had no contact with the participant until the debriefing.

The evaluator's form contained the feedback manipulation. There were five questions on the form: "I would like to be in a small class with the other subject," "I would like to work closely with the other subject," "I would like to get to know the other subject better," I would enjoy being roommates with the other subject," and "I would like to be close friends with the other subject." The social acceptance condition consisted of the first two

\footnotetext{
${ }^{1}$ We used a large number of confederates because this study spanned four academic quarters (almost 18 months). The study took a long time to complete because Black students constituted only $3 \%$ of the campus population at the time.
} 
items with the second highest ratings $(+3)$ and the final three items with the highest ratings $(+4)$. The rejection condition consisted of zero ratings for the first three items, -1 for the fourth item, and -2 for the fifth item. Following the review of the evaluator's form, the experimenter returned to the room, took the envelope, and gave the participant the attributions questionnaire.

Word-finding task. Upon participants' completion of the attribution questionnaire, we connected the rooms in which the participant and confederate sat, but this time they could see and hear each other over large (27 in. [68.5 cm]) television monitors. We then provided instructions for the cooperative word-finding task (similar to the game of Boggle), which required participants to find words in an 8 letter $\times 8$ letter matrix. Participants were instructed that if the two participants performed to a stated criterion, they would each earn a $\$ 5$ bonus. Just before they began the task, they completed emotion ratings. Then, the task began and lasted 4 min. The dyad alternated finding words; the confederate, who had a list of valid words displayed on their computer monitor, responded with words in a predetermined timing schedule. We tracked the number of words participants found as an indicator of performance. At the end of the task, we disconnected the rooms. We then unhooked the sensors and began the debriefing. Prior to the debriefing, we probed for suspicion, taking care to ascertain that the participants were not suspicious of the feedback or of their partners.

\section{Measures}

Physiological measures. Cardiac and hemodynamic measures were recorded noninvasively according to psychophysiological guidelines (e.g., Sherwood et al., 1990). A Minnesota (Chapel Hill, NC) model 304B impedance cardiograph, a Cortronics model 7000 continuous blood pressure monitor, and a Coulbourn (Allentown, PA) model S75-11 electrocardiograph amplifier/coupler provided the physiological signals. Impedance cardiograph and electrocardiograph recordings provided continuous measures of cardiac performance. In impedance cardiography, a Mylar tape electrode system provides basal transthoracic impedance and the first derivative of basal impedance. Two pairs of tapes are used to encircle the participant at the neck and at the torso and are secured with electrodes. A $4 \mathrm{~mA}$ AC $100 \mathrm{kHz}$ current passes through the two outer electrodes and measures basal impedance from the two inner electrodes. The electrocardiograph recordings were obtained with a Standard Lead II configuration (right arm, left leg, and right leg ground). A Cortronics blood pressure monitor provided continuous noninvasive recordings of blood pressure. An interactive software program (Kelsey \& Guethlein, 1990) was used to record and score the cardiac and hemodynamic data.

We differentiated activational (challenge) and inhibitional (threat) states with $\mathrm{CV}$ reactivity (i.e., changes from baseline) focusing on $\mathrm{VC}, \mathrm{CO}$, and total peripheral resistance (TPR), the latter derived from blood pressure and $\mathrm{CO}$ with the formula $(\mathrm{MAP} / \mathrm{CO}) \times 80$, where MAP is mean arterial pressure. We then differentiated high arousal positive emotions from anger by examining magnitude differences in cardiac responses, specifically VC and HR.

Self-reports. Upon reviewing the evaluator's form, participants completed a scale assessing their attributions for the feedback. Embedded in theoretically irrelevant attributions for the feedback (e.g., to participant's religion, personality, and gender) were two items related to the evaluator's prejudice: "Indicate the degree to which each influenced the other student's evaluation of you: (1) the evaluator was prejudiced; and (2) the evaluator discriminated against me." We combined these two items into a composite measure of attributions to discrimination $(\alpha=.67)$.

We measured participants' emotional states immediately preceding the cooperative task (and hence, following feedback), using 10 items from Stephan and Stephan's (1985) intergroup anxiety measure. Participants were instructed to indicate how much of each state (ease, awkwardness, self-consciousness, anxiety, acceptance, confidence, irritation, defensiveness, suspicion, and certainty) they were feeling right now, from -4 to +4 . We used these responses to form three indexes related to the predictions: externally directed negative emotions/anger (defensive and irritated; $\alpha=.82$ ), internally directed negative emotions (awkward, anxious, and self-conscious; $\alpha=.68$ ), and positive emotions (accepting, confident, at ease, and certain; $\alpha=.83$ ).

Behavioral observation and coding. Black and White men and women $(N=11 ; 6$ Black and 5 White) from a different university were trained to code the videotaped cooperative task. Training consisted of a group instructional session, followed by everyone scoring the same 10 participants and determining reliability across those participants. Interrater reliability was high (alphas ranged from .72 to .90 for emotions; $\alpha=.92$ for the behavioral variable). Once consistency was established, each task exchange was scored by two coders: one White and one Black. We were interested in four categories of emotion and behavior: external negative emotion, internal negative emotion, positive emotion, and vigilance. We operationalized vigilance as the number of times the participant looked away from the computer with the letter matrix on it and toward their partner during the word-finding task. By looking away from the computer, participants undermined their performance because they were losing time that could be spent finding a word. Coders also rated participants on relevant emotions from the Positive and Negative Affectivity Schedule (Watson, Clark, \& Tellegen, 1988). We focused on the same three indexes of emotion described earlier: external negative emotions (irritable and hostile; $\alpha=.82$ ); internal negative emotions (ashamed, nervous, distressed, upset, guilty, and jittery; $\alpha=.88$ ); and positive emotions (proud, attentive, inspired, and strong; $\alpha=.67$ ).

\section{Results}

During debriefing, 4 participants expressed suspicion regarding the authenticity of the feedback. We analyzed data with and without these participants, and no significant differences were observed between the full sample and the reduced sample. We present the data below with the suspicious participants excluded.

Various time points from the physiological data were unscorable because of faulty sensors, loss of signal, or noisy signals. Thus, the physiological data have variable degrees of freedom. Videotapes of 7 additional participants were impossible to code, either because of the quality of the video or because the video was cut off during the interaction.

\section{Data: Baseline and Speech Reactivity}

Mean VC, CO, HR, TPR, and MAP values were calculated for each minute within each rest and task period. We began by 
examining the last minute of the baseline for differences based on participants' race, evaluators' race, and/or feedback manipulation. Though random assignment was successful and there were no baseline differences in $\mathrm{CV}$ responses due to feedback or evaluator's race, there were differences in $\mathrm{VC}$ between White participants and Black participants, $F(1,106)=12.16, p<.0007$. Black participants exhibited a shorter preejection period $(M=102.4$, $S D=12.27)$ than did White participants $(M=111.7, S D=$ 15.00). Because of these baseline differences, we conducted all subsequent analyses examining $\mathrm{VC}$ reactivity by controlling for participants' baseline VC.

We then examined $\mathrm{CV}$ responses during the speech that occurred prior to the feedback manipulation. There were no differences in responses by evaluator's race or participant's race. It is important to note that the speech was not a face-to-face speech, which appears to more reliably lead to differences in CV reactivity as a result of the situational context (Mendes, Blascovich, Hunter, Lickel, \& Jost, 2007).

\section{Analytic Strategy}

Hypotheses testing began with an examination of the various dependent variables (CV reactivity, self-reports, attributions, performance, and observers' ratings) and the three independent variables (participant's race, evaluator's race, and feedback) in a series of $2 \times 2 \times 2$ analyses of variance (ANOVAs). We first examined whether the three-way interactions were significant. We obtained significant three-way interactions for most of the critical dependent variables: attributions to discrimination, self-reported external negative emotion (i.e., anger), $\mathrm{CV}$ responses (CO and TPR), performance, and observers' coding indexing vigilance and positive emotion. A complete summary of the full model ANOVAs are presented in Table 1.
We then decomposed the significant three-way interactions by examining the effects of participant's race and evaluator's race separately for the rejection conditions and the acceptance conditions. To conduct these simple effects tests, we used the overall mean square error and degrees of freedom found in Table 1. Significant two-way interactions were then further examined by simple effects tests, within participant's race, to determine whether the effect for evaluator's race was significant. Finally, we tested our a priori predictions regarding differences between Black participants and White participants paired with different-race partners, which we tested using planned contrasts. Specifically, we examined whether Black participants paired with White evaluators differed from White participants paired with Black evaluators. Nonsignificant differences are characterized as symmetrical effects and significant differences are characterized as asymmetrical effects. We also examined participant race effects in same-race pairings, and we never observed any significant race effects. That is, within both feedback conditions, Black participants paired with Black evaluators yielded patterns of findings similar to White participants paired with White evaluators. Means and standard deviations are found in Table 2.

\section{Attributions}

Not surprisingly, participants were more likely to attribute the cause of feedback to discrimination after social rejection than they were to attribute the cause of feedback to discrimination after social acceptance, $F(1,110)=29.59, p<.001$. Furthermore, participants, in general, were more likely to attribute feedback to discrimination when the evaluators were White than when the evaluators were Black, $F(1,110)=6.76, p<.01$. However, the predicted three-way interaction was significant, $F(1,110)=7.35$, $p<.008$. To decompose this interaction, we conducted simple

Table 1

Summary of Effects From ANOVAs Testing the Participant's Race $\times$ Evaluator's Race $\times$ Feedback

\begin{tabular}{|c|c|c|c|c|c|c|c|c|c|c|}
\hline \multirow[b]{2}{*}{ Dependent variable } & \multirow[b]{2}{*}{$M S E$} & \multirow[b]{2}{*}{$\begin{array}{c}\text { P Race } \\
F \text { test }\end{array}$} & \multirow[b]{2}{*}{$\begin{array}{c}\text { E Race } \\
F \text { test }\end{array}$} & \multirow[b]{2}{*}{$\begin{array}{c}\mathrm{F} \\
F \text { test }\end{array}$} & \multirow[b]{2}{*}{$\begin{array}{l}\mathrm{P} \times \mathrm{F} \\
F \text { test }\end{array}$} & \multirow[b]{2}{*}{$\begin{array}{c}\mathrm{E} \times \mathrm{F} \\
F \text { test }\end{array}$} & \multirow[b]{2}{*}{$\begin{array}{c}\mathrm{P} \times \mathrm{E} \\
F \text { test }\end{array}$} & \multicolumn{3}{|c|}{$\mathrm{P} \times \mathrm{E} \times \mathrm{F}$} \\
\hline & & & & & & & & $r^{2}$ & $d f$ & $F$ test \\
\hline Attributions to discrimination & 0.64 & 0.81 & $6.76^{*}$ & $29.59^{* * * *}$ & 1.58 & 0.56 & 3.11 & .31 & 1,110 & $7.35^{* *}$ \\
\hline \multicolumn{11}{|l|}{ Emotion and motivation } \\
\hline External negative & 2.74 & 0.52 & 1.11 & $31.66^{* * * *}$ & 0.03 & 0.16 & 0.65 & .26 & 1,110 & $4.58^{* * *}$ \\
\hline Internal negative & 2.59 & 0.06 & 0.12 & 1.54 & 0.43 & 0.24 & 0.17 & .03 & 1,110 & 0.31 \\
\hline Positive & 2.18 & $5.05^{*}$ & 1.09 & $7.72^{* * *}$ & 1.22 & 0.04 & 0.69 & .13 & 1,110 & 0.00 \\
\hline \multicolumn{11}{|l|}{ CV reactivity } \\
\hline $\mathrm{VC}^{\mathrm{a}}$ & 102.3 & 0.62 & 0.17 & 0.85 & 2.80 & 0.40 & 1.18 & .20 & 1,102 & 2.31 \\
\hline $\mathrm{CO}$ & 2.42 & 0.70 & 3.80 & 1.14 & 1.22 & 0.09 & 0.59 & .14 & 1,102 & $8.13^{* *}$ \\
\hline TPR & 67817 & 0.21 & 1.72 & 1.66 & 1.53 & 1.85 & 0.80 & .18 & 1,102 & $15.02^{* * * *}$ \\
\hline Performance $^{\mathrm{b}}$ & 22.0 & $5.62^{*}$ & 1.56 & 0.06 & 0.17 & 1.01 & 0.09 & .30 & 1,108 & $8.26^{* *}$ \\
\hline \multicolumn{11}{|l|}{ Behavioral observation } \\
\hline Vigilance & 3.78 & 1.08 & 0.26 & 0.02 & 3.11 & 0.58 & 0.97 & .09 & 1,98 & $3.96^{*}$ \\
\hline External negative & 0.41 & 0.86 & 0.21 & 1.08 & 0.21 & 0.00 & 2.85 & .07 & 1,103 & 3.10 \\
\hline Internal negative & 0.32 & 0.01 & 0.39 & 0.02 & 1.96 & 0.19 & 1.34 & .03 & 1,103 & 0.07 \\
\hline Positive & 0.31 & 0.60 & 3.63 & 1.30 & 0.58 & 1.59 & 0.66 & .11 & 1,103 & $4.91^{*}$ \\
\hline
\end{tabular}

Note. $\quad N=118$. The degrees of freedom $(d f)$ for the three-way interactions were the same as that for the other main effects and interactions. ANOVAs $=$ analyses of variance; $M S E=$ mean square error; $\mathrm{P}=$ participant; $\mathrm{E}=$ evaluator; roman $\mathrm{F}=$ feedback; $\mathrm{CV}=$ cardiovascular; $\mathrm{VC}=$ ventricular contractility; $\mathrm{CO}=$ cardiac output; TPR $=$ total peripheral resistance.

${ }^{a}$ All analyses with VC were conducted controlling for baseline VC. ${ }^{\mathrm{b}}$ Analyses shown for performance were conducted controlling for past experience with similar types of word games.

${ }^{*} p<.05 .{ }^{* * *} p<.01 .{ }^{* * * *} p<.001$. 
Table 2

Summary of Means, Standard Deviations, and Effects From Primary Dependent Variables

\begin{tabular}{|c|c|c|c|c|c|c|c|c|c|c|}
\hline \multirow[b]{3}{*}{ Dependent variable } & \multicolumn{4}{|c|}{ Rejection feedback } & \multicolumn{5}{|c|}{ Acceptance feedback } & \multirow[b]{3}{*}{$\mathrm{P} \times \mathrm{F}$} \\
\hline & \multicolumn{2}{|c|}{ Black participant } & \multicolumn{2}{|c|}{ White participant } & \multirow[b]{2}{*}{$\mathrm{P} \times \mathrm{E}$} & \multicolumn{2}{|c|}{ Black participant } & \multicolumn{2}{|c|}{ White participant } & \\
\hline & $\begin{array}{c}\text { Black } \\
\text { evaluator }\end{array}$ & $\begin{array}{l}\text { White } \\
\text { evaluator }\end{array}$ & $\begin{array}{c}\text { Black } \\
\text { evaluator }\end{array}$ & $\begin{array}{l}\text { White } \\
\text { evaluator }\end{array}$ & & $\begin{array}{c}\text { Black } \\
\text { evaluator }\end{array}$ & $\begin{array}{l}\text { White } \\
\text { evaluator }\end{array}$ & $\begin{array}{c}\text { Black } \\
\text { evaluator }\end{array}$ & $\begin{array}{l}\text { White } \\
\text { evaluator }\end{array}$ & \\
\hline $\begin{array}{l}\text { Attributions to } \\
\text { discrimination }\end{array}$ & $1.8(0.87)$ & $2.9(0.98)$ & $2.5(0.87)$ & $2.3(0.84)$ & $9.71^{* *}$ & $1.7(0.9)$ & $1.8(0.7)$ & $1.2(0.4)$ & $1.6(0.7)$ & 0.47 \\
\hline \multicolumn{11}{|l|}{ Emotion and motivation } \\
\hline External negative & $-1.4(1.9)$ & $-0.7(1.8)$ & $-0.4(1.4)$ & $-1.5(2.0)$ & $4.20^{*}$ & $-2.4(1.8)$ & $-3.3(1.2)$ & $-2.6(1.6)$ & $-2.6(1.4)$ & 0.92 \\
\hline Internal negative & $0.8(2.0)$ & $0.5(1.4)$ & $0.4(2.0)$ & $0.3(1.2)$ & 0.01 & $-0.1(1.8)$ & $0.2(1.3)$ & $0.3(1.3)$ & $0.04(1.6)$ & 0.48 \\
\hline Positive & $0.7(1.7)$ & $0.8(1.7)$ & $0.1(1.6)$ & $0.7(1.2)$ & 0.32 & $1.8(1.1)$ & $1.8(1.2)$ & $0.6(1.5)$ & $1.1(1.6)$ & 0.37 \\
\hline \multicolumn{11}{|l|}{ CV Reactivity } \\
\hline $\mathrm{VC}^{\mathrm{a}}$ & $8.8(10.4)$ & $15.8(8.0)$ & $19.4(11.4)$ & $15.9(12)$ & $3.55 \dagger$ & $14.7(14.4)$ & $13.5(9.5)$ & $12.2(9.6)$ & $12.7(8.7)$ & 0.17 \\
\hline $\mathrm{CO}$ & $0.5(2.1)$ & $1.1(1.3)$ & $1.5(2.1)$ & $-0.09(1.2)$ & $6.43^{*}$ & $0.8(1.1)$ & $-0.5(1.0)$ & $0.7(1.7)$ & $0.7(1.2)$ & $3.11^{\dagger}$ \\
\hline TPR & $37.9(274)$ & $-202.3(216)$ & $-161.1(342)$ & $74.3(169)$ & $11.18^{* *}$ & $-97.4(201)$ & $184.8(417)$ & $-33.2(177)$ & $-48.6(131)$ & $4.52^{*}$ \\
\hline Performance & $10.5(4.9)$ & $13.2(4.5)$ & $15.9(5.6)$ & $13.2(2.7)$ & $3.92^{*}$ & $14.1(6.1)$ & $9.9(4.8)$ & $13.7(5.9)$ & $14.0(6.4)$ & $3.99^{*}$ \\
\hline \multicolumn{11}{|l|}{ Behavioral observation } \\
\hline Vigilance & $1.9(2.6)$ & $1.5(1.4)$ & $1.8(1.8)$ & $2.1(2.4)$ & 0.49 & $1.5(1.5)$ & $3.1(2.5)$ & $1.6(1.2)$ & $0.9(0.9)$ & $4.55^{*}$ \\
\hline External negative & $1.2(0.4)$ & $1.7(0.8)$ & $1.6(0.8)$ & $1.20(0.4)$ & $6.02^{*}$ & $1.3(0.7)$ & $1.4(0.8)$ & $1.2(0.4)$ & $1.2(0.6)$ & 0.02 \\
\hline Internal negative & $1.5(0.5)$ & $1.2(0.3)$ & $1.5(0.9)$ & $1.5(0.8)$ & 0.80 & $1.6(0.6)$ & $1.5(0.9)$ & $1.3(0.3)$ & $1.4(0.6)$ & 1.19 \\
\hline Positive & $1.8(0.6)$ & $1.9(0.7)$ & $1.9(0.6)$ & $1.7(0.5)$ & 0.97 & $2.2(0.6)$ & $1.5(0.3)$ & $2.0(0.5)$ & $2.0(0.6)$ & $4.55^{*}$ \\
\hline
\end{tabular}

Note. The standard deviations are in parentheses. $\mathrm{P}=$ participant; $\mathrm{E}=$ evaluator; $\mathrm{CV}=$ cardiovascular; $\mathrm{VC}=$ ventricular contractility; $\mathrm{CO}=$ cardiac output; TPR $=$ total peripheral resistance.

${ }^{a} \mathrm{VC}$ reactivity included $\mathrm{VC}$ baseline as a covariate because of race differences observed at baseline.

${ }^{\dagger} p<.10 .{ }^{*} p<.05 .{ }^{* * *} p<.01$.

effects tests within the social rejection condition and within the social acceptance condition.

Within the social rejection condition, the Participant $\times$ Evaluator race interaction was significant, $F(1,110)=9.71, p<.01$. As expected, Black participants were more likely to attribute rejection to discrimination when paired with White evaluators than when paired with Black evaluators, $F(1,110)=14.18, p<.001$. Among White participants, the direction of the means was consistent with predictions-more attributions to discrimination when the evaluator was Black than when the evaluator was White-but this simple effect was not significant, $F(1,110)=1.01$, ns. Comparisons of responses within the different-race dyads revealed that Black participants paired with White evaluators were more likely to attribute rejection to discrimination $(M=2.9, S D=0.98)$ than were White participants paired with Black evaluators $(M=2.5$, $S D=0.87)$, although this difference was not significant, $F(1$, $110)=1.75, n s$. In sum, Black participants were more likely to attribute rejection to discrimination in a different-race interaction than in a same-race interaction, but among the different-race dyads, there were no significant differences between Black participants and White participants.

As the main effect for feedback revealed, attributions to discrimination were low following social acceptance. None of the simple effects and none of the planned contrasts were significant $\left(F_{\mathrm{S}}<1\right)$.

\section{Emotion Ratings}

We then examined the self-reported emotion ratings that participants completed prior to the cooperative task but following the feedback. As expected, there were main effects for feedback. Participants who received social acceptance feedback reported more positive emotion than those who received social rejection feedback, $F(1,110)=7.72, p<.007$. Similarly, participants reported more external negative emotion when they received social rejection feedback than when they received social acceptance, $F(1$, $110)=31.66, p<.001$. Consistent with our predictions, however, the three-way interaction for external negative emotions was significant, $F(1,110)=4.58, p<.04$.

Again, we decomposed the interaction by first examining the effects of the interaction of participant's race and evaluator's race separately for social rejection and social acceptance conditions. Among those who received social rejection feedback, the Participant $\times$ Evaluator race interaction was significant, $F(1,110)=$ $4.20, p<.05$. White participants rejected by a Black evaluator reported more external negative emotions than did White participants rejected by a White evaluator, $F(1,110)=3.85, p<.052$. Similarly, Black participants rejected by a White evaluator reported more anger than did those rejected by a Black evaluator, though this effect was not significant, $F(1,110)=2.70, p<.10$, Cohen's $d=.31$. We then compared the means from Black and White participants paired with different-race partners. In support of the symmetrical prediction, Black and White participants did not significantly differ in their reports of external negative emotions $(F<1)$. We did not hypothesize or observe differences in external negative emotion among the groups who received social acceptance feedback.

\section{Responses}

To test our predictions for $\mathrm{CV}$ reactivity, we focused on the first minute of the task because cardiac habituation can occur quickly, thus differences in cardiac responses related to challenge and 
threat are most pronounced in the earlier minutes. However, the effects we observed for the first minute persisted for the entire 4 min of the task. The three-way interactions were observed for $\mathrm{CO}$, $F(1,102)=8.13, p<.006$, and for TPR, $F(1,102)=15.02, p<$ .001 . The three-way interaction for $\mathrm{VC}$, controlling for baseline VC, was not significant, $F(1,102)=2.31, p<.13$.

We hypothesized that social rejection from a same-race partner would result in $\mathrm{CV}$ responses consistent with threat (lower $\mathrm{CO}$ and higher TPR), whereas rejection from a different-race partner would result in activational $\mathrm{CV}$ responses (relatively higher $\mathrm{CO}$ and lower TPR). Consistent with predictions, we observed significant Participant $\times$ Evaluator race interactions for $\mathrm{CO}, F(1,102)=$ $6.43, p<.05$, and for TPR, $F(1,102)=11.18, p<.05$. Decomposing the two-way interactions revealed significant (or near significant) differences by evaluator's race for Black participants, for $\mathrm{CO}, F(1,102)=3.10, p<.08$, and for TPR, $F(1,102)=6.38$, $p<.013$. Black participants rejected by Black evaluators exhibited significantly greater increases in vascular resistance and exhibited less cardiac efficiency than did those rejected by White evaluators (see Table 2 and Figure 2). Similar patterns of reactivity were observed among White participants for CO, $F(1,102)=8.33, p<$ .01 , and for TPR, $F(1,102)=6.12, p<.02$. In general, rejection from a same-race partner resulted in increased TPR and decreased $\mathrm{CO}$ (i.e., a threat pattern of $\mathrm{CV}$ reactivity), whereas rejection from a different-race partner resulted in decreased TPR and increased $\mathrm{CO}$ (i.e., an activational pattern of $\mathrm{CV}$ reactivity). An examination of the effects within the different-race dyads revealed no effects for participant's race. Both White and Black participants rejected by different-race partners exhibited activational $\mathrm{CV}$ patterns $(F \mathrm{~s}<1)$.

Our predictions following social acceptance were that a samerace partner would engender $\mathrm{CV}$ reactivity consistent with activational responses (higher $\mathrm{CO}$ and lower TPR), whereas positive feedback from a different-race partner might engender $\mathrm{CV}$ reactivity threat (lower CO and higher TPR). The Participant $\times$ Evaluator race interactions were significant for TPR, $F(1,102)=4.52$, $p<.036$, and near significant for CO, $F(1,102)=3.11, p<.08$ (Figure 3). Among Black participants, those paired with White evaluators exhibited significantly lower CO reactivity $(M=-0.5$, $S D=1.0)$ and greater TPR reactivity $(M=184.8, S D=417)$ than did those paired with Black evaluators (CO: $M=0.8, S D=1.1$; TPR: $M=-97.4, S D=201)$, for $\mathrm{CO}, F(1,102)=4.89, p<.03$, and for TPR, $F(1,102)=8.22, p<.005$. Black participants who received positive social feedback from White evaluators exhibited $\mathrm{CV}$ reactivity consistent with threat, whereas Black participants who received positive feedback from Black evaluators exhibited $\mathrm{CV}$ reactivity consistent with challenge. The simple effects tests among White participants were not significant $(F \mathrm{~s}<1)$. White participants who received social acceptance feedback exhibited $\mathrm{CV}$ responses consistent with challenge states, regardless of the race of the evaluator. Planned contrasts confirmed the asymmetry, for $\mathrm{CO}, F(1,102)=4.84, p<.03$, and for TPR, $F(1,102)=5.21$, $p<.025$. Black participants exhibited threat $\mathrm{CV}$ responses in different-race pairings, whereas White participants exhibited challenge responses in different-race pairings.

\section{Performance}

We operationalized performance as the number of words identified by the participant during the word-finding task. We observed

\section{Negative Evaluation}
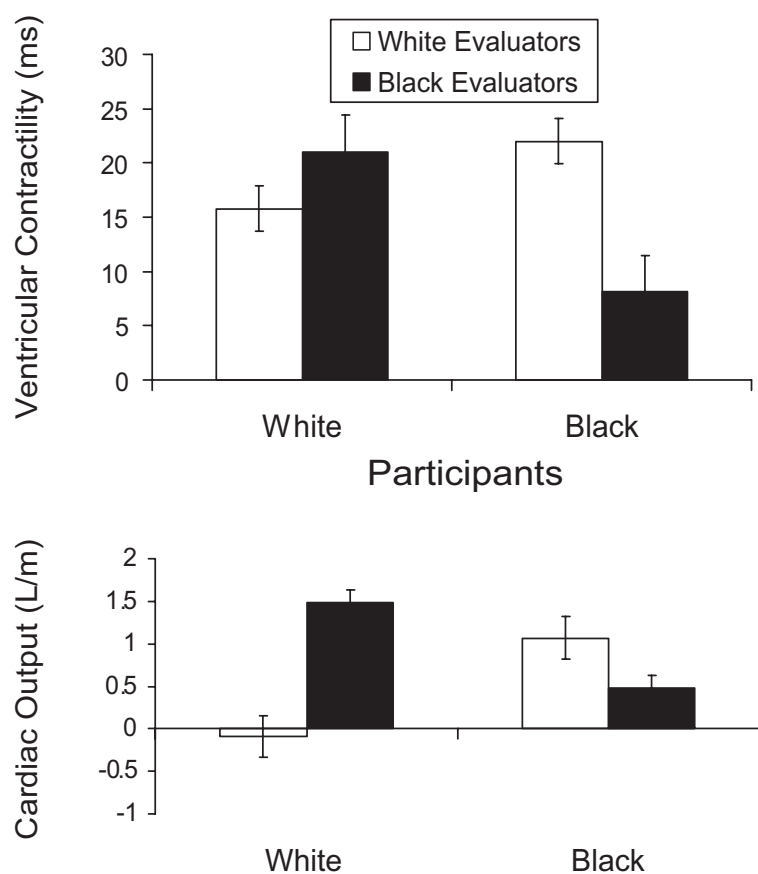

Participants

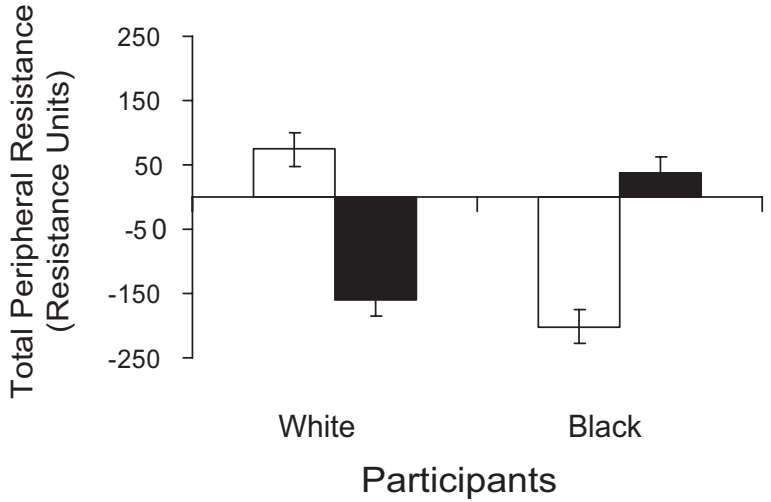

Figure 2. Cardiovascular reactivity from the first minute of the cooperative task following rejection, by participant's race and evaluator's race. The error bars indicate the standard error of the means.

a main effect for race, $F(1,108)=5.62, p<.01$ (on average, White participants found more words than Black participants); however, it is important to note that White participants were more likely to report that they played a similar word game (44\%) in the past than were Black participants (29\%). Because past experience with similar games is an important predictor of performance, we controlled for past experience in all analyses. We again observed the three-way interaction, $F(1,108)=8.26, p<.005$.

We predicted that participants who showed activational responses would perform better than those who showed an inhibitional response. Following the confirmation of the predictions with $\mathrm{CV}$ reactivity, we anticipated that those who were rejected by a different-race evaluator would perform better than would those 


\section{Positive Evaluation}
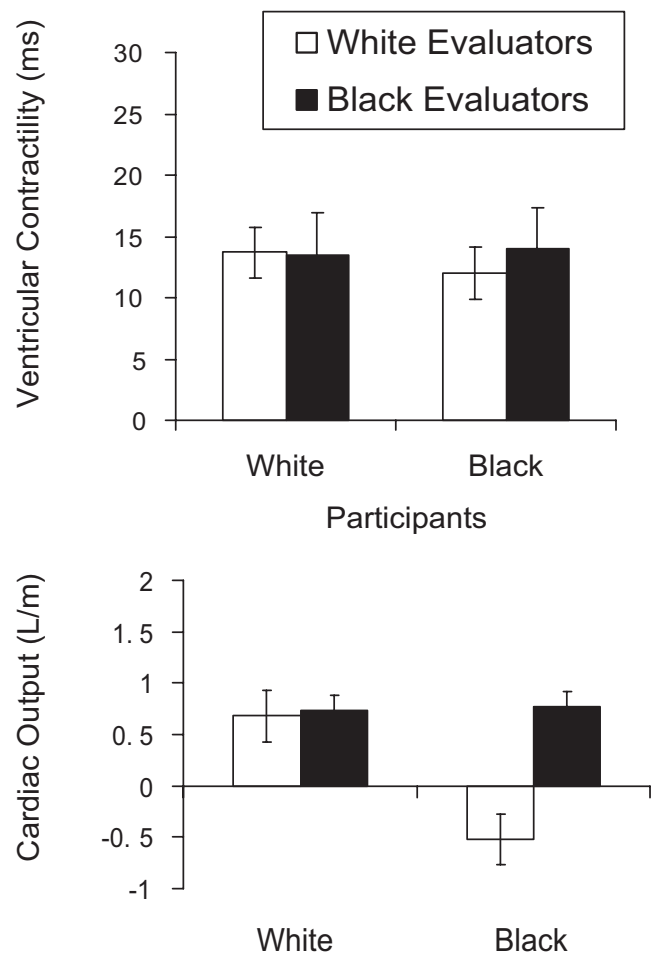

Participants

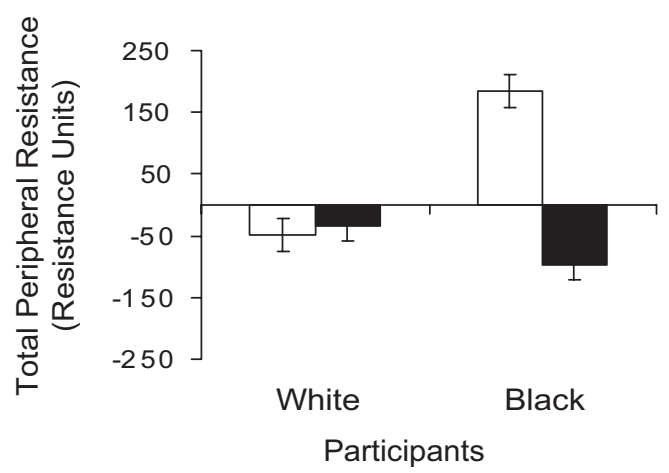

Figure 3. Cardiovascular reactivity from the first minute of the cooperative task following social acceptance, by participant's race and evaluator's race. The error bars indicate the standard error of the means.

rejected by a same-race evaluator. Consistent with the predictions, the Participant $\times$ Evaluator race interaction was significant, $F(1$, $108)=3.92, p<.05$. Among Black participants, those rejected by White evaluators performed better than did those rejected by Black evaluators, though this was short of significance, $F(1,108)=2.65$, $p<.10$, Cohen's $d=.57$. Similarly, among White participants, those rejected by Black evaluators performed better than did those rejected by White evaluators, but again this effect was not significant, $F(1,108)=2.83, p<.09$, Cohen's $d=.61$. In general, participants rejected by a different-race partner performed (marginally) better than did those rejected by a same-race partner. We then examined the performance effects within the different-race pairings. Even in light of the participant race main effect described above, the difference between Black participants paired with White evaluators (adjusted $M=13.2, S D=4.5$ ) and White participants paired with Black evaluators (adjusted $M=15.9, S D=$ 5.6) was not significant, $F(1,108)=2.15, p<.15$.

Among those who received social acceptance feedback, the Participant $\times$ Evaluator race interaction was significant, $F(1$, $108)=3.99, p<.048$. The simple effects test among Black participants was significant, $F(1,108)=5.61, p<.02$. Black participants performed better when paired with Black evaluators who gave positive feedback, compared with Black participants paired with White evaluators. Among White participants, the effect for evaluator's race was not significant $(F<1)$. The planned contrast comparing Black participants with White evaluators and White participants with Black evaluators was also significant, $F(1$, $108)=5.86, p<.025$. Black participants paired with White evaluators performed worse than did White participants paired with Black evaluators.

\section{Behavior}

Our final dependent variables were from the behavioral coding, in which coders (blind to the social feedback condition) rated the extent to which participants appeared vigilant (monitored the other participant) and displayed internal negative emotions (e.g., shame), external negative emotions (e.g., anger), and positive emotions during the word-finding task. The three-way interactions were confirmed for vigilance, $F(1,98)=3.96, p<.05$, and for positive emotions, $F(1,103)=4.91, p<.03$. The interaction for external negative emotions was just short of significance, $F(1$, $103)=3.10, p<.08$, Cohen's $d=.03$.

Among those who received social rejection, the two-way interactions were not significant for vigilance or positive emotions. We predicted that those paired with different-race evaluators who had just given them rejecting social feedback would show more anger than would those rejected by same-race evaluators. Even though the omnibus interaction was just short of significant, because we had a priori predictions regarding this effect, we tested the Participant $\times$ Evaluator race interaction, which was significant, $F(1$, $103)=6.02, p<.05$. Among Black participants, those rejected by White evaluators were perceived as appearing angrier than were those rejected by Black evaluators, $F(1,103)=4.57, p<.04$. Similarly, among White participants, those rejected by Black evaluators appeared angrier than did those rejected by White evaluators, $F(1,103)=4.04, p<.05$. Again, the effects within differentrace settings appeared to be symmetrical in that White participants rejected by Black partners were rated as exhibiting similar levels of external negative emotions $(M=1.6, S D=0.8)$ as Black participants rejected by White partners $(M=1.7, S D=0.8$; $F<1)$.

Among those who received social acceptance feedback, we hypothesized that Black participants might be uncertain of or suspicious of social acceptance from White evaluators, resulting in increased vigilance. We tested this hypothesis by examining our behavioral measure of vigilance-how often participants monitored their partner during the cooperative task. We observed a significant two-way interaction, $F(1,98)=4.55, p<.05$. Among Black participants, the evaluator's race resulted in a significant 
effect, $F(1,98)=4.74, p<.05$. Black participants interacting with White evaluators monitored them more during the task than Black participants interacting with Black evaluators. Among White participants, the race of the evaluator was not significant $(F<1)$. Planned contrasts comparing the intergroup pairings yielded a significant effect as well, $F(1,105)=4.17, p<.05$. Black participants paired with White evaluators monitored them more often $(M=3.1, S D=2.5)$ than did White participants paired with Black evaluators $(M=1.6, S D=1.2)$.

We also hypothesized that positive emotion would be greater following social acceptance from a same-race partner than following social acceptance from a different-race partner. Analysis of coders' ratings of how much positive emotion the participants exhibited during the cooperative task revealed a significant Participant $\times$ Evaluator race interaction, $F(1,103)=4.56, p<.05$. As predicted, among Black participants, those paired with a samerace evaluator displayed more positive emotion than did those assigned to a different-race evaluator, $F(1,103)=11.06, p<$ .002. The simple effects test was not significant among White participants. Similar to the other measures, Black participants positively evaluated by White partners were rated as expressing less positive emotion $(M=1.5, S D=0.3)$ than White participants positively evaluated by Black evaluators $(M=2.0, S D=0.5)$, $F(1,105)=5.85, p<.05$.

\section{Differentiating CV Activational Responses: Positive Emotions Versus Anger}

We observed two meta-conditions that resulted in $\mathrm{CV}$ reactivity consistent with activational patterns-social acceptance from same-race partners and social rejection from different-race partners. $^{2}$ However, we expected these two conditions to engender very different emotions. Specifically, we expected social acceptance from same-race partners to engender positive emotions (pride, confidence), and we expected social rejection from different-race partners to engender anger. We found initial confirmation for these predictions with behavioral observation and, to a lesser extent, self-reported emotions.

We then turned to our predictions regarding differentiating anger from positive emotions using cardiac variables, specifically, VC and HR reactivity. We predicted that anger would yield larger cardiac responses than would positive emotions; hence, we expected that VC and HR changes would be higher in the rejection/ different-race conditions than in the acceptance/same-race conditions. An ANOVA revealed significant differences in VC (averaged across the task) between conditions in the direction hypothesized, $F(1,54)=4.34, p<.04$. Participants rejected by differentrace partners exhibited greater $\mathrm{VC}(M=17.15, S D=10.3)$ than did those who received positive feedback from same-race partners $(M=11.5, S D=10.0)$. The same analysis performed on HR changes revealed significant differences between conditions in the predicted direction as well, $F(1,55)=8.31, p<.006$. Again, the discrimination condition resulted in greater increases in $\operatorname{HR}(M=$ $11.73, S D=8.8)$ than did social acceptance by a same-race partner $(M=5.69, S D=6.8)$.

Finally, we examined correlations between cardiac variables (VC and HR) and observed emotions. We predicted that VC responses would be related to greater anger, but only in conditions in which anger was evoked-the rejection/different-race condi- tions. Consistent with these predictions, VC changes were positively and significantly related to expressed anger (average $r=$ $.53, p<.01$ ) as were HR changes (average $r=.36, p<.05$ ). In the same-race and positive feedback conditions, these relationships were not observed (for VC and expressed anger, average $r=-.07$, $n s$; for HR, average $r=-.23, n s)$. Furthermore, we expected that positive emotions would be related to a dampening of $\mathrm{CV}$ responses (see Fredrickson, Mancuso, Branigan, \& Tugade, 2000). The results for this effect were weaker but were in the predicted direction. In the same-race and positive feedback condition, less $\mathrm{VC}$ was related to greater observer-rated positive emotion $(r=$ $-.31, p=.052)$. HR changes were also negatively related to positive emotion following positive feedback, but the relationship was weak $(r=-.19, n s)$. These analyses show some support for the idea that $\mathrm{VC}$ and $\mathrm{HR}$ responses tend to increase as the intensity of anger increases.

\section{Ancillary Analyses}

To explore possible mechanisms of the performance effects observed, we examined relationships between $\mathrm{CV}$ reactivity and performance. Consistent with the idea that threat responses impair cognitive performance, we observed that the greater the $\mathrm{CV}$ threat pattern, the fewer words participants found (for $\mathrm{CO}, r=.31, p<$ .007 ; for TPR, $r=-.22, p<.03$ ). As expected, VC and HR did not predict performance. These relationships lend support to the argument that threat reactivity is part of the profile of physiological responses that may be associated with performance decrements and may operate in stereotype threat situations (Blascovich, Spencer, Quinn, \& Steele, 2001) as well as other threatening or distressing situations.

\section{Discussion}

We predicted that social rejection and social acceptance would be interpreted and experienced differently in intraracial versus interracial encounters. Rejection in an interracial context led to more activational $\mathrm{CV}$ reactivity, better performance, and more self-reported and nonverbal displays of anger. For most of the findings, the effects were symmetrical in that Whites' responses to rejection by a Black evaluator were similar to Blacks' responses to rejection by a White evaluator. However, it is important to note that the interaction for attributions to discrimination were primarily a result of Black participants perceiving rejecting feedback as more likely being due to discrimination when evaluated by White partners compared with Black partners, whereas White participants did not significantly rate rejecting feedback as being more due to discrimination based on the evaluator's race. Black participants might have been more likely to claim discrimination, given the same circumstances, than White participants because of exposure to past discrimination or because of the historical and cultural

\footnotetext{
${ }^{2}$ We also examined the cardiac differences between positive emotion and anger, using the additional condition: White participants paired with Black evaluators who received positive feedback. The results are similar to what is reported above, however this particular condition was not included in the main analyses because the grouping was post hoc. Furthermore, the imbalance in the within cell $n$ s provides misleading conclusions regarding the relationships between cardiac reactivity and emotions.
} 
milieu in which they reside (Crocker \& Major, 1989). Contrary to expectations, we did not find that intragroup rejection would bring about more self-reported or observed internal negative emotions than would intergroup rejection, though performance and $\mathrm{CV}$ responses did suggest more impairment and inhibitional responses following intraracial social rejection.

In contrast, receiving positive feedback from a same-race partner resulted in more activational physiological responses, better performance, and more positive emotion than did receiving positive feedback from a different-race partner. These latter effects were asymmetrical, however, with the interaction driven primarily by Black participants. In comparison with White participants positively evaluated by a Black partner, Black participants positively evaluated by White partners exhibited CV responses consistent with threat, performed less well, and showed less positive emotion and more vigilance during the cooperative task.

\section{Implications and Extensions for Attributional Ambiguity Theory}

The current research extends prior work on attributional ambiguity in a number of ways. Most important, it shows how attributional ambiguity is manifested physiologically and behaviorally, as well as emotionally, in ongoing interracial interactions. In addition, it demonstrates the important point that rejection in intergroup encounters results in similar patterns of responses for members of majority groups (Whites) as it does for members of minority groups (Blacks). Members of both groups appeared angered by social rejection feedback when it came from a differentrace evaluator rather than from a same-race evaluator. This symmetrical pattern illustrates that rejection that is perceived as unjust and perceived as possibly due to discrimination might engender anger responses, regardless of race of the target. Third, it demonstrates that the attributional ambiguity stemming from receiving positive feedback from a majority group member in a context in which expression of prejudice against minorities is strongly discouraged can, ironically, engender threat and impair performance among minorities.

Past work on the consequences of attributional ambiguity has focused primarily on implications for self-esteem (e.g., Crocker et al., 1991; Major et al., 2003) and has shown that conditions that lead to the highest rates of attributions to discrimination are also most likely to buffer self-esteem from rejection. Additionally, in early attributional ambiguity theory, it was argued that buffered self-esteem following negative feedback might stem from a deflection of self-blame to other blame, thus protecting the self. Thus, we argued that deflecting blame for rejection from self to other would result in more anger responses as well as activational physiological responses. However, it is possible that buffered self-esteem was a defensive response that masked underlying distress, which is similar to the idea of repressive coping. In this case, we would likely have observed less self-reported distress coupled with greater physiological threat responses. In contrast, we observed strong activational responses. Therefore, we believe these data extend earlier attributional ambiguity work by demonstrating that situations in which discrimination is a plausible attribution can result in activational motivational responses rather than in threat or disengagement.
Crocker et al. (1991) also found that Black participants reported a less negative mood than did White participants, following rejection by a White partner. Their measure of negative mood, however, combined internal (e.g., sad, depressed, discontent, gloomy) and external (e.g., angry, mad, vindictive) moods. In distinguishing external from internal negative emotions, we predicted and observed specific emotional reactions following intraracial rejection that differed from interracial rejection (discrimination). Thus, the extensions to attributional ambiguity theory offered in the present study do not simply provide measurement advances (physiological and nonverbal measures) or design advances (examining majority and minority groups) but also provide clarification of the motivational and emotional responses underlying attributionally ambiguous situations.

This research also extends attributional ambiguity theory by demonstrating how positive feedback in intergroup encounters can be attributionally ambiguous for members of minority groups but can be less so for majority groups. Black participants' responded favorably to social acceptance from a partner of their own race but negatively to social acceptance from a White partner. White participants, in contrast, responded relatively favorably to social acceptance from both White and Black partners. It is important to note that the partners were blind to feedback condition, thus the asymmetrical responses cannot be due to White partners behaving differently in the social acceptance condition than in the rejection condition.

What accounts for this asymmetry? We believe that Blacks experience social acceptance from Whites as attributionally ambiguous (Major, 2005). Strong social norms have emerged in the United States that discourage the display of prejudice by Whites against Blacks, especially on college campuses. Whites report being motivated to behave in an unprejudiced way for external as well as internal reasons (Plant \& Devine, 1998), respond in a more prejudiced way on implicit than on explicit measures of prejudicial attitudes (Dovidio, Kawakami, Johnson, \& Howard, 1997), and even show a positive bias in their evaluations of Blacks (Harber, 1998; Mendes et al., 2002; Vanman, Paul, Ito, \& Miller, 1997). As a result, we find it unsurprising that Black participants may come to doubt the sincerity of positive feedback from White peers, especially when such feedback appears to be based on limited information. The inability to trust feedback or accurately gauge another's feelings is, in turn, likely to engender uncertainty. This can be aversive and threatening (e.g., Mendes et al., 2007) and can interfere with accurate knowledge of one's abilities (Aronson \& Inzlicht, 2004). Thus, positive feedback from Whites to Blacks may have an ironic and unintended negative impact, particularly if the positive regard is perceived as disingenuous.

Because our study was designed, in part, to examine effects of attributions of discrimination, we acknowledge that there are methodological factors that might have influenced our results. In our study, we asked participants to rate attributions that might account for the feedback they received. In explicitly engaging the attributional process, we were, in effect, priming participants to think about discrimination as a plausible reason for rejection. Without these primes, we would expect that individuals who chronically expect or anticipate discrimination would respond similarly to our participants here; however, it is not clear that those who do not hold chronic prejudice expectations would have thought of discrimination as a likely cause for the feedback; instead, they might 
have been threatened by rejection, regardless of the intergroup context. In addition, it is important to recognize other theories that could account for our findings. For example, system justification theory (e.g., Jost, Banaji, \& Nosek, 2004) might have predicted that majority group members' responses to rejection by a minority group engendered anger, not because it was deemed discriminatory but rather because it violated the hegemony believed to exist between different racial groups, specifically Whites believing they have higher social status than do Blacks.

\section{Extensions for the Biopsychosocial Model}

The current research advanced prior research and theory in psychophysiology by differentiating positive emotions from anger within the same activational pattern of responses (see also Herrald $\&$ Tomaka, 2002). We found that rejection from a different-race partner and social acceptance from a same-race partner both resulted in an activational pattern of physiology despite engendering different emotions. Thus, despite the apparent similarity of $\mathrm{CV}$ responses in these two conditions, we argue that they can reflect very different underlying emotional states because the motivational states are orthogonal to valence. We predicted that conditions that evoked anger (e.g., rejection by an outgroup member) would engender greater sympathetic activation than conditions that evoked challenge (e.g., acceptance by an ingroup member). As expected, we found that cardiac changes were greater for the rejection/different-race conditions than for the acceptance/samerace conditions and that the greater the expressed anger, the greater the increase in ventricular contractility and HR.

In future research, it will be important to measure other $\mathrm{CV}$ responses that could possibly differentiate positive emotions from anger. One such parameter is CV recovery, in which anger should result in a much slower trajectory of cardiac recovery than would positive emotions. A second parameter is an index of parasympathetic influence. Some recent evidence suggests that anger may result in decreases in cardiac vagal reactivity (vagal withdrawal) (Demaree \& Everhart, 2004; Sloan et al., 2001), whereas positive emotions may result in increases in cardiac vagal reactivity (Porges, 2003). Finally, it is important to note that the cardiac differences we observed could simply reflect emotional intensity rather than emotional specificity.

\section{Limitations}

In this study, we examined White and Black participants in early adulthood who were all students at a 4-year university. This sample limits generalizability, when we consider how discrimination affects those of lower SES, limited education, and older age. Though this limitation is not trivial and does circumscribe the conclusions, it can also be construed as an advantage to this research because, on average, the participants were currently exposed to similar environmental influences. The younger sample also meant that there were fewer baseline physiological differences between the two groups. We did, however, observe baseline differences in VC. This difference could be due to underlying biology, anxiety associated with participating in an experiment, or even early signs of vulnerability to hypertension because of cumulative effects of discrimination. Though even after controlling for these baseline differences, we still observed effects of interracial encounters on stress reactivity.

\section{Future Directions: Implications for Pathways of Discrimination to Health}

This study provided evidence that responses to actions perceived to be discriminatory resulted in more activational $\mathrm{CV}$ responses and anger, whereas rejection that could not easily be attributed to external causes (e.g., evaluator's bias) was more likely to result in threat responses. This provides a fertile framework regarding linking patterns of physiological responses to possible health outcomes. Racial disparities are large, with Blacks at least 2 times more likely to be hypertensive than are Whites. Furthermore, disparities in coronary heart disease are increasing (National Center for Health Statistics, 2003; Willems, Saunders, Hunt, \& Schorling, 1997). One explanation for racial disparities in health is that perceived discrimination engenders physiological stress responses that are harmful to health (Clark et al., 1999). In this research, rejection from different-race partners, compared with rejection from same-race partners, was more likely to be attributed to discrimination and was associated with increased anger; this rejection also led to a larger cardiac response. Several lines of evidence suggest that physiological responses associated with anger, such as increased cardiac responses, are associated with the development of hypertension and are directly or indirectly linked to coronary heart disease (Anderson, McNeily, \& Myers, 1991; Matthews, Salomon, Brady, \& Allen, 2003; see Matthews, 2005, for a review). Repeated anger expression has been found to be linked to coronary heart disease via physiological processes that can compromise the CV system (atherosclerosis and hypertension) or can bring about acute events that can initiate critical diseases (e.g., stroke and myocardial infarction; see Leventhal \& PatrickMiller, 2000; Smith, 2006). So, even though, in the short term, anger may deflect self-blame, protect self-esteem, and result in collective action, when anger is repeatedly experienced, it may create excessive wear and tear on CV functioning. Blacks are more likely than are Whites to perceive and/or experience discrimination and, to the extent that they respond with anger and have increased cardiac reactivity, this may partly explain why Blacks are at increased health risk.

Threat or inhibitional responses may have harmful effects on health as well. Though still speculative, threat responses may make one more vulnerable to immune- and age-related diseases (Irwin, Daniels, Smith, Bloom, \& Weiner, 1987; Leventhal \& PatrickMiller, 2000). Research has identified links between negative internal emotions such as sadness, depression, and anxiety and diseases such as cancer, reduced immunological functioning, and hypertension (S. Cohen \& Herbert, 1996; Irwin et al., 1987; Kiecolt-Glaser, McGuire, Robles, \& Glaser, 2002). These links suggest the provocative hypothesis that social rejection that is internally attributed might be associated with one pathway to disease, whereas discrimination and hostility might be associated with a different pathway. Future research should focus on these distinct pathways and the emotional and psychological states associated with them. 


\section{References}

Anderson, N. B., McNeily, M., \& Myers, H. (1991). Autonomic reactivity and hypertension in Blacks: A review and proposed model. Ethnic Disparities, 1, 154-170.

Aronson, J., \& Inzlicht, M. (2004). The ups and downs of attributional ambiguity: Stereotype vulnerability and the academic self-knowledge of African American college students. Psychological Science, 15, 829836.

Ayduk, O., Mischel, W., \& Downey, G. (2002). Attentional mechanisms linking rejection to hostile reactivity: The role of 'hot' versus 'cool' focus. Psychological Science, 13, 443-448.

Barger, S. D., Marsland, A. L., Bachen, E. A., \& Manuck, S. B. (2000). Repressive coping and blood measures of disease risk: Lipids and endocrine and immunological responses to laboratory stressor. Journal of Applied Social Psychology, 30, 1619-1638.

Baumeister, R. F., \& Leary, M. R. (1995). The need to belong: Desire for interpersonal attachments as a fundamental human motivation. Psychological Bulletin, 117, 497-529.

Blascovich, J., \& Mendes, W. B. (2000). Challenge and threat appraisals: The role of affective cues. In J. Forgas (Ed.), Feeling and thinking: The role of affect in social cognition (pp. 59-82). Paris: Cambridge University Press.

Blascovich, J., Mendes, W. B., Hunter, S. B., Lickel, B., \& Kowai-Bell, N. (2001). Perceiver threat in social interactions with stigmatized others. Journal of Personality and Social Psychology, 80, 253-267.

Blascovich, J., Spencer, S. Quinn, D., \& Steele, C. (2001). African Americans and high blood pressure: The role of stereotype threat. Psychological Science, 12, 225-229.

Blascovich, J., \& Tomaka, J. (1996). The biopsychosocial model of arousal regulation. Advances in Experimental Social Psychology, 28, 1-51.

Brownley, K. A., Hurwitz, B. E., \& Schneiderman, N. (2000). Cardiovascular psychophysiology. In J. T. Cacioppo, L. G. Tassinary, \& G. G. Bernston (Eds.), Handbook of psychophysiology (2nd ed., pp. 224-264). New York: Cambridge University Press.

Bullock, S. C., \& Houston, E. (1987). Perceptions of racism by Black medical students attending White medical schools. Journal of the National Medical Association, 79, 601-608.

Cacioppo, J. T., Bernston, G. G., Larsen, J. T., Poehlmann, K. M., \& Ito, T. A. (2000). The psychophysiology of emotion. In M. Lewis \& J. M. Haviland-Jones (Eds.), Handbook of emotion (2nd ed., pp. 173-191). New York: Guilford Press

Cacioppo, J. T., Hawkley, L. C., \& Bernston, G. G. (2003). The anatomy of loneliness. Current directions in psychological science, 12, 71-74.

Cheney, D., Seyfarth, R., \& Smuts, B. (1986, December 12). Social relationships and social cognition in nonhuman primates. Science, 234, 1361-1366.

Clark, R. Anderson, N. B., Clark, V. R., \& Williams, D. R. (1999). Racism as a stressor for African Americans: A biopsychosocial model. American Psychologist, 54, 805-816.

Cohen, G. L., Steele, C. M., \& Ross, L. D. (1999). The mentor's dilemma: Providing critical feedback across the racial divide. Personality and Social Psychology Bulletin, 25, 1302-1318.

Cohen, S., \& Herbert, T. B. (1996). Health psychology: Psychological factors and physical disease from the perspective of human psychoneuroimmunology. Annual Review of Psychology, 47, 113-142.

Crocker, J., Cornwell, B., \& Major, B. (1993). The stigma of overweight: Affective consequences of attributional ambiguity. Journal of Personality and Social Psychology, 64, 60-70.

Crocker, J., \& Major, B. (1989). Social stigma and self-esteem: The self-protective properties of stigma. Psychological Review, 96, 608630

Crocker, J., Voelkl, K., Testa, M., \& Major, B. (1991). Social stigma: The affective consequences of attributional ambiguity. Journal of Personality and Social Psychology, 60, 218-228.
Demaree, H. A., \& Everhart, D. E. (2004). Healthy high-hostiles: Reduced parasympathetic activity and decreased sympathovagal flexibility during negative emotional processing. Personality and Individual Differences, 36, 457-469.

Dickerson, S., Gruenewald, T. L., \& Kemeny, M. E. (2004). When the social self is threatened: Shame, physiology, and health. Journal of Personality, 72, 1191-1216.

Dovidio, J. F., Kawakami, K., Johnson, B., \& Howard, A. (1997). On the nature of prejudice: Automatic and controlled processes. Journal of Experimental Social Psychology, 33, 510-540.

Eisenberger, N. I., Lieberman, M. D., \& Williams, K. D. (2003, October 10). Does rejection hurt? An fMRI study of social exclusion. Science, 302, 290-292.

Feldman Barrett, L. (2006). Valence is a building block of emotional life. Journal of Research in Personality, 40, 35-55.

Fredrickson, B. L., Mancuso, R. A., Branigan, C., \& Tugade, M. M. (2000). The undoing effect of positive emotions. Motivation and Emotion, 24, 237-258.

Harber, K. D. (1998). Feedback to minorities: Evidence of a positive bias. Journal of Personality and Social Psychology, 74, 622-628.

Harmon-Jones, E., \& Allen, J. B. (1998). Anger and frontal brain activity: EEG asymmetry consistent with approach motivation despite negative affective valence. Journal of Personality and Social Psychology, 74, $1310-1316$

Herrald, M., \& Tomaka, J. (2002). Patterns of emotion-specific appraisal, coping, and cardiovascular reactivity during an ongoing emotional episode. Journal of Personality and Social Psychology, 83, 434-450.

Ickes, W. (1984). Compositions in Black and White: Determinants of interaction in interracial dyads. Journal of Personality and Social Psychology, 47, 330-341.

Irwin, M., Daniels, M., Smith, T. L., Bloom, E., \& Weiner, H. (1987). Impaired natural killer cell activity during bereavement. Brain, Behavior, and Immunity, 1, 98-104.

Jost, J. T., Banaji, M. R., \& Nosek, B. A. (2004). A decade of system justification theory: Accumulated evidence of conscious and unconscious bolstering of the status quo. Political Psychology, 25, 881-920.

Kaiser, C. R., \& Miller, C. T. (2001). Stop complaining! The social costs of making attributions to discrimination. Personality and Social Psychology Bulletin, 27, 254-263.

Kelsey, R. M., \& Guethlein, W. (1990). An evaluation of the ensemble averaged impedance cardiogram. Psychophysiology, 27, 24-33.

Kiecolt-Glaser, J. K., McGuire, L., Robles, T. F., \& Glaser, R. (2002) Psychoneuroimmunology influences on immune function and health. Journal of Consulting and Clinical Psychology, 70, 537-547.

Leary, M. R., Gallagher, B., Fors, E., Buttermore, N., Baldwin, E., Kennedy, K., \& Mills, A. (2003). The invalidity of disclaimers about the effects of social feedback on self-esteem. Personality and Social Psychology Bulletin, 29, 623-636.

Levenson, R. W., Ekman, P., \& Friesen, W. V. (1990). Voluntary facial action generates emotion specific autonomic nervous system activity. Psychophysiology, 27, 363-384.

Leventhal, H., \& Patrick-Miller, L. (2000). Emotions and physical illness: Causes and indicators of vulnerability. In M. Lewis \& J. M. HavilandJones (Eds.), Handbook of emotion (2nd ed., pp. 523-537). New York: Guilford Press.

Major, B. (2005). New perspectives on stigma and psychological wellbeing. In S. Levin \& C. van Laar (Eds.), Stigma and group inequality: Social psychological perspectives. Mahwah, NJ: Erlbaum.

Major, B., Quinton, W. J., \& McCoy, S. K. (2002). Antecedents and consequences of attributions to discrimination: Theoretical and empirical advances. Advances in Experimental Social Psychology, 34, 251330 .

Major, B., Quinton, W. J., \& Schmader, T. (2003). Attributions to discrim- 
ination and self-esteem: Impact of group identification and situational ambiguity. Journal of Experimental Social Psychology, 39, 220-231.

Matthews, K. A. (2005). Psychological perspectives on the development of coronary heart disease. American Psychologist, 60, 783-796.

Matthews, K. A., Salomon, K., Brady, S. S., \& Allen, M. T. (2003). Cardiovascular reactivity to stress predicts blood pressure rise in adolescence. Psychosomatic Medicine, 65, 410-415.

Mendes, W. B., Blascovich, J., Hunter, S., Lickel, B., \& Jost, J. T. (2007). Threatened by the unexpected: Physiological responses during social interactions with expectancy-violating partners. Journal of Personality and Social Psychology, 92, 698-716.

Mendes, W. B., Blascovich, J., Lickel, B., \& Hunter, S. (2002). Challenge and threat during social interactions with White and Black men. Personality and Social Psychology Bulletin, 28, 939-952.

National Center for Health Statistics (2003). Health, United States. Hyattsville, MD: Author.

Plant, A., \& Devine, P. (1998). Internal and external motivation to respond without prejudice. Journal of Personality and Social Psychology, 75, 811-832.

Porges, S. W. (2003). The polyvagal theory: Phylogenetic contributions to social behavior. Physiology \& Behavior, 79, 503-513.

Richeson, J. A., \& Shelton, J. N. (2003). When prejudice does not pay: Effects of interracial contact on executive function. Psychological Science, 14, 287-290.

Richeson, J. A., Trawalter, S., \& Shelton, J. N. (2005). African Americans' implicit racial attitudes and the depletion of executive function after interracial interactions. Social Cognition, 23, 336-352.

Sherwood, A., Allen, M. T., Fahrenberg, J., Kelsey, R. M., Lovallo, W. R., \& van Dooren, L. J. P. (1990). Methodological guidelines for impedance cardiography. Psychophysiology, 27, 1-23.

Sinha, R., Lovallo, W. R., \& Parsons, O. A. (1992). Cardiovascular differentiation of emotions. Psychosomatic Medicine, 54, 422-435.

Sloan, R. P., Bagiella, E., Shapiro, P. A., Kuhl, J. P., Chernikhva, D., Berg, J., \& Myers, M. M. (2001). Hostility, gender, and cardiac autonomic control. Psychosomatic Medicine, 63, 434-440.
Smith, T. W. (2006). Personality as risk and resilience in physical health Current Directions in Psychological Science, 15, 227-231.

Stephan W. G., \& Stephan, C. W. (1985). Intergroup anxiety. Journal of Social Issues, 41, 157-175.

Stephan, W. G., \& Stephan, C. W. (2000). An integrated threat theory of prejudice. In S. Oskamp (Ed.), Reducing prejudice and discrimination. Mahwah, NJ: Erlbaum.

Stroud, L. R., Tanofsky-Kraff, M., Wilfley, D. E., \& Salovey, P. (2000). The Yale Interpersonal Stressor (YIPS): Affective, physiological, and behavioral responses to a novel interpersonal rejection paradigm. Annals of Behavioral Medicine, 22, 204-213.

Vanman, E. J., Paul, B. Y., Ito, T. A., \& Miller, N. (1997). The modern face of prejudice and structural features that moderate the effect of cooperation on affect. Journal of Personality and Social Psychology, 73, 941-959.

Vorauer, J. D., \& Turpie, C. A. (2004). Disruptive effects of vigilance on dominant group members' treatment of outgroup members: Choking versus shining under pressure. Journal of Personality and Social Psychology, 87, 384-399.

Watson, D., Clark, L. A., \& Tellegen, A. (1988). Development and validation of brief measures of positive and negative affect: The PANAS scales. Journal of Personality and Social Psychology, 54, 1063-1070.

Weinberger, D. A., Schwartz, G. E., \& Davidson, R. J. (1979). Lowanxious, high-anxious, and repressive coping styles: Psychometric patterns and behavioral and physiological responses to stress. Journal of Abnormal Psychology, 88, 369-380.

Willems, J. P., Saunders, J. T., Hunt, D. E., \& Schorling, J. B. (1997) Prevalence of coronary heart disease risk factors among rural Blacks: A community-based study. Southern Medicine Journal, 90, 814-820.

Williams, K. (2001). Ostracism: The power of silence. New York: Guilford Press.

Received October 13, 2006

Revision received June 26, 2007

Accepted July 1, 2007 